\title{
THE VOICE OF SOCIETY AND THE CRISIS: THE POTENTIAL AND LIMITS OF REFLEXIVITY AND CIVILITY
}

Víctor Pérez-Díaz

Analistas Socio-Políticos Research Center, Madrid

\section{/// Introduction}

The year that symbolically marks the end of the twentieth century and the beginning of the new millennium is 1989. For some, the triumph of the free world augured an end to history, but in reality it has led to an unstable modus vivendi, a "new normality" characterized by a high degree of uncertainty. This situation has placed history and the capacity of human agency to guide it at the centre of public debate and politics. This article has been written under the impact of the sensation of uncertainty, and is influenced by two key ideas: the central importance of human agency and the voice of society, of the common people, in contrast to the (frequent) overestimation of structure and the (habitual) overestimation of the protagonism of elites and counter-elites. History, this intertwining of agency and structure, is like an open drama. A group of actors-in particular, the political classact on a stage in front of an audience. But the audience is active (Perelman \& Olbrechts-Tyteca 1971) and does not limit itself to applauding or booing the actors. It speaks and acts on its own; it intervenes in the drama.

Today's debate seems dominated by a generalized sensation of global crisis, affecting not only the economy and politics, but society and culture as well. In reality, society's current restlessness has existed since well before 1989 but is now becoming increasingly palpable. Some sociologists see the period from the end of the 1960s to the early 1980s as a transition from a world dominated by processes of morphostasis (which assure continuity in the fundamental aspects of the structure and culture of a society), 
to one characterized by morphogenetic processes, through which society enters a path of continuous generation and regeneration of new forms of organization and orientation in the world: a path of deep discontinuities (Archer 2007). This transition from morphostasis to morphogenesis places the focus on the strategic capacity of human agency to orient itself in a context of growing uncertainty and complexity. This capacity, in turn, depends on the degree and quality of the reflexivity and relationality of the agency in question, as well as the civic impulse that emerges from the connection between both dimensions. Reflexivity, relationality, and civic impulse define the capacity of agency to grow or improve in situations of disorder. I refer to reflexivity (Archer 2007, 2010) as the exercise of agents' capacity in considering their bidirectional relationship with their social context, and the resulting quality and degree of their self-awareness. Here I insist on the limits, degrees, ambiguities, and ambivalence of that reflexivity. Relationality (Donati 2011) refers to a system of social relations in which agents are involved, with special attention to common goods, such as community building and civil forms of politics. ${ }^{1}$

Both liberal democracy and the market economy seem greatly impacted by the current crisis, in different ways and to different degrees across countries. The prospects for globalization and technological change, growing inequality, disaffection with the political class among wide layers of society, migratory flows, terrorism, and the contrast between the exponentially growing volume of information and the sensation that "noise" and uncertainty are also growing - all converge in the perception of this moment as one of deep, prolonged crisis that may even worsen.

In this paper I explore the strategic capacity of human agency in such times by presenting and analysing an opinion survey carried out in May 2016, ${ }^{2}$ and I develop an argument about a given collective agent, the Spanish citizenry at the time, whose will is articulated in a set of attitudes and opinions. I adopt the perspective of an interpretive social science, in which the meaning of action for agency itself, understood in its context, has crucial importance (Gadamer 1996; Pérez-Díaz 1980), and in which the strength of the argument depends on the plausibility of the reconstruction of this action and of the situation to which it responds. This is a perspective attentive to the cognitive and moral potential and limits of the agents

\footnotetext{
${ }^{1}$ This essay combines both problématiques (reflexivity and relationality) as one step more in the development of the issue of the intensity of agency (Pérez-Díaz 2015). It is a revised and much shortened version of Pérez-Díaz (2017).

2 This survey was sponsored by the Funcas Foundation, with a sample size of 1,210 respondents. Details in Pérez-Díaz (2017).
} 
involved. In this case, I present the voice of the audience in the form of responses to a questionnaire, weaving together the questions, the responses, and my commentary. This is a tentative reconstruction of the voice of the citizenry and applies what Davidson (1974) called the "principle of charity," understanding what is said by addressing what they plausibly want to say, its coherence and its context. In this case, the voice presents a significant degree of coherence and of correspondence with reality.

Of course, human agents, whether elites or common people, have a limited capacity for coherence and for understanding reality, and our capacity for deliberation with others and with ourselves is also limited. Nevertheless, we think and act against the backdrop of internal deliberation, weighing arguments for and against different positions, so that our mental processes and our actions are dialogic (Bakhtine 1970: 284, 298). In addition, they are situated within the sphere of a relationship with others; they are approaches and responses to the solicitations of others. This relationality (Donati 2011), which is carved into our experience, means that our attitudes and opinions are inscribed in a conversation with a multiplicity of actors. The end result of this combination of reflexivity and relationality is a changing complexity in the voice of the agent in question-in this case, the voice of the audience in a public sphere. This voice is not only not exempt from ambiguity and ambivalence, but to a certain extent is characterized by them (Smelser 1998). It tends to reflect not rigid but relatively fluent positions, which incorporate different degrees of uncertainty and internal deliberation, but which, in this case, allow for a crucial modicum of self-awareness and of civility (Hall 2013; March \& Olsen 1995; Smith 2002).

In fact, the Spanish citizens send three main messages. First, they opt for a European course for the country, and, on issues of substantive policy, for a range of positions that are consistent with the experience of recent Spanish and European generations in terms of a convergence (and debate) between the traditions of social democracy and conservative liberalism. Second, they are rather careful and attentive in regard to the task of recreating a political community. Third, and most emphatically, they support and ask for civil forms of doing politics. In sending these messages the citizens draw on socio-cultural resources, and on forms of reflexivity and of their relational world (whose potential and limits I explore). In particular, I address the nature of society's relation with the political class and with itself, and certain cultural resources (economic knowledge, historical narratives) that map these relationships in space and time, the global context, and 
the past. In this way, I set out to consider the current moment as an open drama.

\section{/// Messages: Europe as the Horizon, and a Range of Moderate European-style Public Policies}

The Spaniards have felt themselves to be in a situation of deep unease for years, and this has formed an alert and distrustful society. Yet they think they know the general direction their country should go and to which world they belong: Europe, the euro, European kinds of politics and policies. What countries do the Spanish consider proper models for Spain? When asked about a country that "could be a model for the Spanish economy," the respondents' positions are unmistakable. The models are European countries: more specifically, those of central and northern Europe: Germany (24.2\%), Sweden, Finland, Norway, and Denmark (21.1\%), as well as France, the Netherlands, Switzerland, and the United Kingdom $(14.5 \%)$. In the Spanish imagination, these countries are market economies open to global capitalism, which forms an inseparable part of the countries' social and political contexts. They are states capable of managing the current economic crisis or limiting its worst effects, and with strong welfare systems; they operate within a framework where social tensions over public policies appear not as radical conflicts that question the system but as the normal conflicts of liberal democracies and plural societies. These countries are neighbours and are familiar to the Spanish, in the sense that they belong, as does Spain, to the European family.

Other questions also reflect the great importance the European Union has for Spain: $72.6 \%$ of the Spanish believe that "Spain should remain in the euro zone." This is not expressing a mere duty, convenience, or interest; it is also the manifestation of the durable state of being part of a complex reality. As of now, a Europe of nations, a Europe with a story, is perhaps a bit unclear in our explicit memory, but alive in innumerable "places in memory" (Nora 1997). It is the story of a Europe that has functioned from time immemorial as a world of nations in rivalry, imitating each other ad nauseam and existing in the permanent tension of each living in the shadow of the others, always a mutual reference for each other. Today, their rivalries have been pacified and their reciprocal imitation has grown more intense. So far, a destination point has emerged as Europe has tried to respond to the civil wars and totalitarian phenomena of the twentieth century with the institutional framework that characterizes it today. Regarding more recent 
times, we are talking about a collective subject that is engaged in a political debate about the best way to manage the crisis and other important matters (migrations, geopolitical tensions, terrorism, etc.). Thus, we may assume a fundamental attachment by Spaniards to the idea of Europe, and a commitment to it as part of "a natural order of things" (Pérez-Díaz 2013).

At the same time, there are gaps in the Spaniards' installation in Europe, a touch of fragility when the time comes to pinning down their opinions regarding European public policies and current challenges. Thus, $46.5 \%$ think that "to resolve the economic problems of EU countries it is better that each country recuperates greater control over its economic policies," in comparison to $36.6 \%$ who prefer "that the EU plays a more fundamental role in the economic policy of member states." On the contrary, $64.7 \%$ think that "European countries acting together will effectively confront the problem of jihadist or Islamic terrorism in the near future." Yet the percentages are more equal in the case of welcoming refugees, with $46.1 \%$ agreeing that "each country should decide on its own the number of refugees it wants to accept," and $47.6 \%$ preferring "the majority of EU governments deciding" on that number.

In any case, Spanish society's fundamental commitment to a Europe that sets the course clearly reveals a preference for a certain type of social, economic, and political system. This preference is, again, not without some ambivalence, which is crucial, in particular at a moment when the apparent need to make corrections to capitalism is being intensely debated. Grosso modo, Spanish society's vision of capitalism, or the market economy, seems clearly positive. A wide majority (59.5\%) prefer a "free market economy" and not "an economy run by the government" (24.7\%). Moreover, there is a certain underlying optimism regarding the possibility of long-term growth, which is assumed to be inherent to capitalism. In a 2010 survey, which presented respondents with the fact that per capita income in Spain had quintupled in the last fifty years, and asked if they would ascribe this increase to either the spontaneous development of Spanish and international markets or to the effectiveness of Spanish governments' policies, 74.5\% clearly opted for the former (Pérez-Díaz \& Rodríguez 2010: 98). Moreover, a majority tend to accept key aspects of the policies habitually associated with a liberal and conservative attempt to save capitalism in a period of crisis. Thus, $62.1 \%$ accept fiscal equilibrium and support the 2011 reform of the Spanish constitution, which was based on a consensus between the Socialists and the Popular Party to guarantee a balanced public budget across the business cycle. 
However, it is necessary to temper this conclusion by placing it in a broader context that underlines the importance of politics. Several questions reflect ambivalence toward capitalism. On the one hand, there is resistance to excessive criticism of capitalism. This was revealed in a 2009 survey (Pérez-Díaz \& Rodríguez 2010: 98) in which 35.6\% attributed responsibility for the crisis to the failure of capitalism, but $58.9 \%$ attributed it to "abuses" within capitalism. On the other hand, there is a clear refusal to give capitalism an overall positive evaluation, as can be seen, for example, when issues of poverty are discussed. Thus, $39.1 \%$ believe that "the market economy is the economic system that has been shown to be most capable of eradicating world poverty," but 53.9\% think that "it often causes poverty for the majority of the population."

Behind these assessments there is a moral, emotional, and cognitive disposition toward strengthening the protective state, responsible for the welfare of the people. We asked a relatively standard question in this sense and $71.9 \%$ of respondents chose the option that "the state is responsible for all citizens and should take care of those persons that have problems," and only $17.6 \%$ chose that "citizens are responsible for their own welfare and they must take care of the situation themselves when they have problems." At the same time, regarding a guaranteed income, with the state providing all Spanish citizens "a minimum income, just for being citizens and independent of age and economic situation," respondents for and against split by half: $50.8 \%$ and $47.8 \%$ respectively.

The Spaniards' positions on these issues must be understood, at least in part, as based on the moral idea of the economy as oikos, as the domestic economy of a family writ large, or of a nation understood as a sort of shared home, with its distinct and common parts, whose accounts must be balanced for its survival in a context of limited goods (and limited inequalities). This contrasts with the vision of the economy as an open and expanding order in which people are above all attentive to their own interests, the vision that prevails in the business world and even (to a lesser extent) among academics and politicians: in other words, in a great part of the establishment. For them (those "above"), the connection between capitalism and growth seems very strong and common sensical; but for much of society (those "below"), that connection may seem more fragile, as if remnants of the moral economy of times past remain. The establishment may be projecting its own conception on society, believing that that conception is shared and in so doing misunderstanding society, and therefore, 
over-interpreting data such as those regarding the acceptance of the policy of fiscal equilibrium. ${ }^{3}$

Thus, behind the answers given by the respondents there seems to be a vision of a society that differs in important ways from the imagining of a part of the establishment, which, grosso modo, tends to repeat with futuristic flourishes François Guizot's exhortation in the French Chamber of Deputies in 1843: "Enrichissez-vous!" In its simplest version, these elites seem to say that the task of politicians is to achieve a triumphant society, with high levels of growth, high per capita income, and world influence. But we should place this simple version of things in its immediate semantic context. The complete phrase from Guizot was: "Éclairez-vous, enrichissez-vous, améliorez la condition morale et matérielle de notre France!" The task of enriching oneself was situated in the context of several moral tasks, referring to an appeal to community and to a sense of solidarity. Perhaps this context was already problematic at that time, even in the culture of contemporary elites (and Balzac could be a witness of this); or perhaps it has become even more problematic over time, and the culture of the elites has possibly been relatively degraded.

The truth is that the complexity of the original expression can be lost in today's debates. To somehow recover that complexity, we asked the survey participants some naive questions about the proper goals for Spanish society and polity. Their responses point in a direction that has certain affinities with the moral reading of the economy alluded to before. They were asked "What should be more important in politics: that a country gains wealth and influence in the world, or that its population has a better life and more free time?": $11.6 \%$ preferred the former and $84.1 \%$ the latter. They were also asked "What should the politicians in a country focus their attention on above all: on increasing per capita income and the influence of the country in international affairs, or on increasing the population's free time and level of education?" In this case, $35.9 \%$ preferred the former, and $57 \%$ the latter.

These responses suggest that a traditional moral and apparently precapitalist and even pre-modern language is widespread. It is only apparently pre-capitalist because, in reality, a reasonable reading of modernity might be akin to that of Karl Polanyi's regarding the embeddedness of the economy in the totality of practices and institutions of social life

\footnotetext{
3 On the moral economy of the past see Thompson (1971), and on the differences in the vision of everyday citizens and economists, see Caplan (2002).
} 
(Granovetter 1985; Polanyi 2001 [1944]; Smelser \& Swedberg 2005; Streeck 2014), thus questioning the factors of production to be characterized as mere commodities or fictitious commodities. In such a case, we would need to look for the meaning of the data, and specifically the economic opinions expressed, as embedded in the totality of the experiences of the social groups in question. We might speculate here that a "little tradition" (Foster 1967; Pérez-Díaz 1991) — a basic alternative culture of the common people, anchored in the experiences of past generations, many of them of a rural character-has remained (Morris \& Manning 2005). But it is still there, perhaps not in its totality, perhaps not completely coherent, perhaps doubtfully, but clearly recognizable.

To reinforce this image of the complexity and ambiguity of the setting that we find, and of the collective imagination of the society in question, we can look at an additional question and the responses. Participants were asked: "Please imagine two types of society, one more innovative but less egalitarian, and another more egalitarian but less innovative, in which would you prefer to live?" A great majority would prefer the second, more egalitarian society $(67.5 \%)$ than the first, more innovative one $(30 \%)$.

In short, this narrative refuses to be neatly located within a black or white alternative, and leaves the door open to various possibilities. We find a nuanced acceptance of capitalism, with fuzzy cultural foundations. This qualified acceptance suggests a willingness to demand or accept changes within a range of possibilities, in a process of continual corrections to the capitalist economy and the welfare state.

\section{/// Messages: The Spanish Political Community as the Main Frame of Reference in the Political Life of The Spanish}

To talk of a course assumes that someone follows it: a specific ship or vessel, with a name, a memory, its own identity. This would be the main "community of reference" for the political life of the population. For the great majority of this survey's respondents, the main frame of reference for their public concerns seems to be not Europe, nor Spain's autonomous regions, but rather the Spanish political community, the Spanish state as a whole.

Again, things are not black or white; collective identities can be diverse and there is an ongoing debate on the distribution of powers between the central government and the regions. Yet the centrality of the Spanish state 
is supported by a large majority (81.8\%), which does not want "a state in which the possibility of autonomous regions becoming independent states is recognized." The centrality of the Spanish state is also supported by the fact that $90.8 \%$ of the respondents feel Spanish, at least to some degree, and only 6.4\% don't feel Spanish at all. (Of course, these sentiments are somewhat different in regions such as Catalonia, in which $14.7 \%$ identify only as Catalans.)

The questions raised here were in regard to whether the Spanish have the impression that Spain as a political community, as a state, will increase, remain the same, or decline as the main reference of political life. Will Spain be capable of resolving collective problems and reflecting the opinions and interests of its people, while maintaining the country's unity, which is now under challenge by Catalan secessionists?

Respondents were asked: "Thinking of the next ten years and taking into account that political life for the Spanish can have three frames of reference (Spain, the autonomous region of residency, and Europe), do you think that Spain will be the main reference in the political life of the Spanish more than it is now, the same as it is now, or less than it is now." More than half (53.1\%) answered that it would be the same as now, 20.4\% responded "more than now" and 22.2\%, "less." Now, identifying Spain as the principal reference in political life implies the centrality of the Spanish state understood in its broad sense, as the whole of both central and regional governments, as it is related to the perception that the Spanish state has the strategic capacities which define its substantive legitimacy, which in turn rests on its capacity to resolve problems, to guarantee the permanency of the community, and to represent its citizens (Pérez-Díaz 2008).

In this regard, the first question was: "Do you believe that the capacity of the Spanish state, that is, the totality of central and regional governments, to resolve the country's problems will have increased, will be the same, or will have declined in the next five years?" The questions that followed this are repetitions of it but with reference, in one case, to the capacity of the state "to guarantee the unity of the Spanish," and in another, "to reflect the opinions and interests of the great majority of Spanish citizens." Looking at the responses, $73.1 \%$ believe that the state's capacity to resolve problems will continue to be the same or will increase; $69.2 \%$ think its capacity to guarantee unity will remain the same or will increase; and $75.1 \%$ believe that its capacity to represent the opinions and interests of society will remain the same or will increase. 


\section{/// Messages About Political Manners: The Civil Forms of Citizens and the Bellicose Forms of Politicians}

Let's make no mistake: in politics "forms are contents." To continually recreate the political community (e.g., by responding adequately to the unease resulting from the economic crisis or the risks of territorial fragmentation) requires managing social relations within it in a specific manner: civil forms foster this recreation, and uncivil forms hinder it.

I have used the image of a ship at sea that follows or searches for a course. But this ship needs to be rebuilt and repaired over and over again if it is to navigate without sinking. And this ship is always at sea, always having to be steered (formulating and implementing public policies, adjusting its internal mechanisms, the division of its powers). In other words, it is always afloat in the agitated environment of the high seas, not in the tranquillity of the port. Repairing it, reconstructing it, must be done, as Otto Neurath suggests, based on our vision of reality at the same time as we are immersed in it, or, according to Quine, such a holistic verification can be done, perhaps entirely, but only through a gradual reconstruction (Quine 1960). The image suggests that the continual recreation of the community in the middle of the open and rough sea requires certain forms of relating onboard. Excluding the possibility of the captain having omnipotent powers, it requires a mix of conversation and coordination, a climate of deliberation and a search for approaches, experiments, and life experiences: what I consider civil forms of politics.

However, an alternative interpretive framework fosters a voluntarist reading of politics as a confrontation between ideas and interests, between friends and enemies, around which every crucial decision is to be made. History becomes then a setting for deploying a will to power. Social recognition and knowledge itself are the result of a Hegelian fight to the death among diverse forms of consciousness, particularly in the interpretation of Kojève (1947). This impulse can easily extend to a conception of the nation (or the people) as a result of the construction of the imaginary, an invention whose creation only awaits a fiat, overflowing with resolution and defiance. All of this leads to a cultural bias that inhibits the development of civil forms, which, with their emphasis on deliberation and exploration, on listening to arguments and addressing diverse experiences, would appear, from a decisionist perspective, to be linked to a problematic and passive attitude toward managing the ongoing crucial problems. 
The image of a ship at sea that requires civility in its forms may be implicit in, and consistent with, a good part of the opinions of the common people. We have seen that, in reference to the substance of public policies, the citizenry sends a message revealing its commitment to a free order open to debate and rectifications, and to a political community that requires effective communication among its members. Regarding the forms of doing politics, the message is even more robust and clear; it questions the manners of the politicians and includes a proposal in favour of civil forms of public debate.

The fact is, $71.4 \%$ of those surveyed believe that "in relation to the controversies over autonomy, nationalisms, etc., the majority of the people would tend to reach agreement, but political leaders tend to promote conflict." In more general terms, $83 \%$ agree with the statement that "many politicians, of all tendencies, tend to discredit their adversaries to divert the public's attention from the fact that, in reality, they are not capable of resolving the country's problems." There is a certain suspicion of deliberate manipulation, which perhaps can be better understood by looking at the responses to other questions. Thus, $63.2 \%$ agree with the statement that "many politicians try to intensify the feelings of hostility of their social base against opposition parties to make compromise between them impossible." Furthermore, $89.1 \%$ believe that "when politicians listen to the points of view of politicians from other parties, they listen to them to refute their arguments rather than being open to incorporating their most reasonable ideas." Note that these opinions do not criticize the diversity of political positions nor the relevancy, for example, of the use of a left/right schema: $53.3 \%$ think that "the notions of right and left are still valid for evaluating the positions taken by the parties and politicians," while 39.1\% do not agree with that. People do not object to the existence of differences in opinion. Rather, they object to how these differences are expressed.

This objection reflects certain basic attitudes toward political life, and a normative and emotional disposition in favour of political practices of deliberation leading to reasonable compromise. So, $83.8 \%$ believe that "public debate should function as a discussion in which everyone has the opportunity to contribute something and to learn," in contrast to $14.2 \%$ who support "a discussion in which different perspectives can be clearly distinguished." In the same sense, $72.3 \%$ think that "what should be most important in political life is that the political parties deliberate, negotiate, and compromise," versus $26 \%$ who think that "the political parties should 
obtain the majority necessary to make decisions as quickly as possible." A wide majority, therefore, is in favour of a deliberative rather than decisionist citizenry. There is a clear message in favour of deliberation and, we may infer, in favour of a sort of collective learning process based on mutual listening and, eventually, the consideration of accumulated experiences.

All this culminates in what seems to be an appeal to a fundamental ontological question, with cognitive, moral and emotional dimensions, concerning the manner in which reality is confronted. I am referring to what can be inferred from the responses to the question: "In current conditions, if you had to choose between two types of politics, which would you prefer?" In choosing between the options that "they have a moral sense and common sense or they have great vision and energy," $77.2 \%$ chose the former and $18.6 \%$ the latter. These and other responses suggest the outlines of a "good society," a society with a good sense which would include common sense (a sense of reality) and a moral sense, and would emphasize a balance between private interests and care of others, solidarity, and even altruism. And we might add, in an aside: when respondents were asked to respond to the following question, "Which of these two options is closer to what you think? : The most important thing in life is to carry out a personal project, although in the process you may ignore to some extent the well-being of others, or, it often makes sense to renounce our personal projects for the good of others," $76 \%$ chose the second option, and $20.7 \%$ chose the first.

The general tenor of the responses suggests that we are encountering two somewhat different moral political languages: that of many politicians (and certain media and experts), and that of many citizens. Many politicians imagine political communication in terms of a supply and demand for policies, and perhaps as a result, they become infected by an abstract, impersonal language that they believe predominates in the markets. Yet political communication is not an issue of marketing; it is a two-way street, with the danger that one or both parties will be confused, leading to misunderstanding or to dead ends. Realist spirits can think that the respondents, in making the above statements theirs, place themselves on an idealistic plane, and entertain themselves with a sort of celestial music. However, underneath this ironic expression may pulsate a deep misunderstanding of politics, because politics involves not only the management of practical problems, but also the celebration and affirmation of a political community. This is what Pericles does in his funeral oration: by enacting a ritual of remembering, he activates a feeling of being together, fighting together, and honouring the dead of the homeland, along with the meaning of the 
legacy that would consequently be transmitted to future generations. In fact, politics is a collective civil performance that is both prosaic and poetic, a moment of reflection and exhortation, of celebration and mourning.

Besides, there are also reasons for thinking that the respondents' idealism can be combined with a sharp sense of reality. This is expressed not only in terms of criticism and even a touch of suspicion of politicians, but also (as we will see in what follows) through their attitudes toward society itself, that is, toward themselves.

\section{/// Socio-cultural Resources: Ambiguity in Political Disaffection}

We have seen that the messages of the citizenry seem to be relatively consistent and constitute a sort of common-sense culture or a sense of what is commonly shared. Now I will address the socio-cultural resources the citizenry have to project these messages in public spaces and to be involved in civic action. I focus on resources related to two interconnected dimensions of the lived culture of the Spanish: relationality and reflexivity. First, I analyse the ambivalent relationship between society and the political class. Then I address the potential and limits of the narrative, and the respondents' understanding of the economy and history - their awareness, say, of the spatial and temporal frame of their common experience. I end by considering some key aspects of the, again, somehow ambivalent relationship of society with itself.

Beginning with what citizens expect from their elites, there is quite a lot of evidence of political disaffection. Clearly, recent swings in the electoral panorama and the decline in the fortunes of the parties that have dominated the Spanish scene for three decades (broadly speaking, the socialists and liberal-conservatives between 1982 and 2015) indicate a notable level of political disaffection; an important factor in this has been the social anxiety caused by the crisis. Disaffection is clear in the results of the survey.

Politicians are seen as not concerned with people like the respondents: $77.3 \%$ agree with the statement that "politicians do not worry much about what people like me think" (a proportion that has increased in the last 35 years-Analistas Socio-Políticos 2016). As found in the 2010 survey, there is a belief that politicians "are different" both because of their personal distance from the crisis and because of what it means for them to belong to a political party. In fact, $76.5 \%$ of respondents thought that it was not true that "many politicians of all tendencies are motivated to resolve the crisis because they suffer its consequences in their personal lives" (Pérez-Díaz 
\& Rodríguez 2010: 165). Politicians are also seen as different because their essential experience as politicians leads the common people to consider them as part of an apparatus. Thus, when asked about "the behaviour of politicians from the party respondents are closest to, regarding debates within the party," $69.2 \%$ thought that "they tend to accept the directives of their leaders, almost without discussion."

Being different, it seems logical that their ways of doings politics would also be different, particularly their way of engaging in public debate (as we have seen concerning the nationalist question and other matters). Furthermore, it may seem also quite logical that politicians are seen as trying to shape the public's attitudes in conformity to their own. In fact, $63.2 \%$ of respondents agree that "many politicians try to intensify the feelings of hostility of their social base toward opposition parties to make a compromise with them impossible."

However, there is also evidence that relativizes the intensity of political disaffection, and suggests an attitude of ambivalence. First, a large majority of Spanish voters have voted for the same or very similar parties over three decades. Only very recently have we begun to observe some electoral tremors. Second, although citizens may have doubts, they support a repertoire of substantive policies that are not very different from those the major political parties offer. Moreover, when the two major parties reach agreement, the public tends to support this compromise, as happened during the democratic transition and has continued to happen: for example, with the above-mentioned introduction of a constitutional clause requiring fiscal balance.

We may add that the vast majority of citizens place themselves on the left-right scale with no apparent problems, which would be almost unthinkable without some kind of attachment to the parties, which are assumed to be the protagonists in the processes through which these symbolic spaces are constructed and reconstructed over and over. Lastly, let's remember that the strategic capacity of the Spanish state is assumed to be to resolve problems, to guarantee the unity of the territory, and to represent citizens. Obviously, this supposedly capable Spanish state is led by $\ldots$ politicians.

As a corollary, I propose that we understand the issue of political disaffection avoiding a dichotomous position. Political disaffection tends to be an issue of degree, and to grow or to diminish as a consequence of learning processes. Even unfulfilled promises can be at the origin of such processes, sometimes feeding the distrust of certain parties and an excess 
of trust in their opponents. For example, the level of disaffection could rise if voters feel that the two parties that promoted the above-mentioned constitutional clause are failing to fulfil their promises to overcome the crisis, although the same experience could induce voters naively to trust new parties that are all promise (as with the current populisms).

\section{/// Socio-cultural Resources: A Limited Narrative and Understanding}

Now I will explore the potential and limits of society's self-awareness as it places itself in a larger spatial and temporal frame. I address the issue of citizens' knowledge in three areas: the economy, Europe, and Spanish history.

To begin with, most citizens' economic knowledge is limited, and they know it. A clear majority (62.9\%) think "that the level of knowledge of the Spanish population regarding how the Spanish economy functions is quite low" or very low (versus 15.3\% who think it is quite high or very high). However, a slight majority also believe that they essentially understand the economy well enough. Respondents were asked: "Do you believe that the complexity of the economy is increasing and becoming more difficult to understand, or that, in reality, although it may be more complex, with common sense and some information, the essential can be understood?" In this case, $52.7 \%$ believe that what is essential about the economy is understood, versus $44.6 \%$ who do not believe that. On the other hand, to put things in context, we may remember that in regard to uncertainty in applying knowledge to practice, citizens are actually in the same position as the economic elites, politicians, and experts-whom citizens might assume have greater mastery of economics than is actually the case. In fact, as has been pointed out many times, the economic crisis is incomprehensible without taking into account the errors and lack of awareness of central banks, banks in general, real estate firms, and others institutions, which engaged in practices that were opaque not only to the public but also often to themselves (Friedman 2009). At the same time, events can leave the political elites behind, as was revealed, for example, by the failure of both the Democratic and Republican candidates for the White House, Barack Obama and John McCain, to anticipate the impending financial crisis in the summer and fall of 2008. As for the experts themselves, the studies of Tetlock (2005) and others have revealed that their modest capacity for anticipating the movements of markets is very similar to that which the dilettanti might have. 
This said, if knowledge of the economy may help people to understand their situation in the world order here and now, history may provide a narrative that places them in a time frame and gives them a sense of identity. The Spanish say they know little of Europe today and of its history, but they must have a diffuse and tacit knowledge of what Europe was and isenough for that knowledge to have an influence on Spain's course, and for the citizens to hold certain European countries as models and to remember parallel experiences that have had a deep impact on both European and Spanish political and economic institutions. In fact, respondents see themselves as not very informed about the workings of European institutions: $75.3 \%$ confess "they know little or nothing about the deliberations and decisions of European leaders in institutions such as the European Council or European Commission." In addition, $77 \%$ believe that "the level of knowledge the Spanish have in general of the history of Europe" is low or very low. If this is the case, the results are disquieting because it would thus be difficult to understand the meaning and consequently the strategies and underlying stories behind what other European countries do and say. Lacking familiarity with these narratives would seem to favour an attitude of ignorance in regard to the task of understanding other Europeans. In addition, not sharing their historical memories, it would not be possible to develop a sense of familiarity with them.

Should we interpret this confession of ignorance literally? My initial discussion of the general direction Spain follows would seem to suggest that Europe is quite present in the Spanish collective imagination. Spanish people must have an implicit and diffuse knowledge of European history, based on the history learned as part of their general education and on their experience of the European space-replete with a past that has become familiar - as migrants, tourists, and students. And there must be an even richer knowledge of the European history of the past century, with its events that were of concern to everyone-a dramatic history marked by civil wars, both European and Spanish, and the spread of totalitarianism and authoritarianism. From these, Europe and Spain have emerged with the institutional fabric of liberal democracy, the market economy, and the plural society that now characterize them.

Two-thirds (66.4\%) of respondents say that "the level of knowledge that the Spanish have of the history of Spain" is quite low or very low, and only $21.9 \%$ say that it is quite high or very high. If this were the case, the poverty of the historical imagination of the people, lacking the thread of an argument and specific details, could be reinforced by a tendency towards 
presentism in the rhetoric of politicians and in the information disseminated by the media.

Again, is this all that needs to be said regarding the Spanish and their sense of history? Probably not, as memory of that which is closest in history must also be taken into account, in particular the democratic transition, understood as a response to the dramatic events of the preceding decades. This is not just a detail, but rather a fundamental event in the narrative of the past as it concerns the present life of the political community. Indeed, it is the defining event that has marked, and still marks, the course of Spain. In fact, when the respondents were asked whether they were proud or not "of the stage of history in Spain from the democratic transition to today," $52.3 \%$ said they feel very or quite proud. Yet, without an adequate narrative, one that is sufficiently persuasive to interest people in public issues, they would lack motivation and a civic impulse. The key to civic passion in ancient societies was fidelity to the memory of ancestors, and, to a lesser extent, to forthcoming generations, as well as (and implicit in the anterior) fidelity to a land consecrated by the gods, whether local or distant. These evocations gave sense to the sacrifices necessary when the health or survival of the res publica was in danger. This happened in the Greece of Pericles, but also in the Roman republic, in late-medieval times, in more-or-lessrevolutionary full modernity, in relation to the nationalist drives of the last two-and-a-half centuries (Greenfeld 2006), and on until the present.

Without a "lived" history and narrative, people lack some significant component of the motivation necessary to generate a public interest, not to mention a civic passion that would imply the sacrifice of private interests - the forgetting or trivialization of history being an indicator of the superficial character of contemporary civic commitment. Ultimately, without a narrative there is no identity, on either a personal or a collective level (Lamont 2000; MacIntyre 2006; Wuthnow 2005). And this afflicts all those without a historical memory, whether ordinary citizens or the elites of the moment.

\section{/// Socio-cultural Resources: Society's Ambivalence Towards Itself, and the Potential and Limits of Civic Commitment}

It is not enough to address citizens' attitudes to, and relation with, the political class, nor to look at the cognitive dimensions, narratives, and understanding that shape citizens' grasp of politics and policies. We have to look into their capacity to transform their messages into effective political 
influence by means of their engagement in civic action. From this perspective, I will now focus my attention on a series of issues related to the civic commitment of the Spanish, such as their interest in politics, their willingness to speak in a certain way about political matters, their experience with and attitudes towards associations, and last but not least the grounding of this combination of reflexivity and relationality in their resources of social trust, and their degree and quality of self-confidence.

I begin by presenting a few positive pieces of evidence. Half (50.6\%) of those surveyed say that they have a lot or quite a bit of interest in politics, versus $48.9 \%$ who say they have little or no interest in politics. The percentage interested in politics is probably the highest since the beginning of the 1980s (Analistas Socio-Políticos 2016). (It may be added that while respondents turn to the media to keep informed about public affairs, they do so from a critical perspective. The great majority, $72.2 \%$, think that "the media informs them about political affairs in a disorderly and confusing manner," versus $24.1 \%$ who believe the media does so in "a clear and orderly manner.")

We can go a step further and consider the associative experience of the respondents. Such experience provides training in the capacity to participate in collective action, with a common interest: first, by participating in discussion and then by undertaking the joint activity. Collective action may itself be aimed at a civic objective, or it may prepare the way, form the dispositions, and provide the necessary instruments for its attainment (Putnam 2000). According to the survey, $23.3 \%$ belong to and are very active in an association, $16.8 \%$ belong to an association but are not very active in it, $13.7 \%$ only pay the fees, and $46.1 \%$ say they do not belong to any association. The attraction of associationism is not only expressed in belonging to associations, but also by the influence people think associations should have in solving the country's problems. When asked about that, $81.7 \%$ believe it should be higher than it is.

We should look at the potential for civic action inscribed in this experience of associationism and in the interest in politics against the backdrop of a society with a critical attitude toward itself. Here we find that, in terms of mentality and life experience, citizens have doubts about their own capacity to act in a coordinated manner. Perhaps the necessary self-confidence and self-esteem to maintain a civic impulse are not at adequate levels. This can be inferred from the responses to questions on generalized social trust, on the frequency of work well done, and on recognizing the merit of doing things well. First, generalized social trust seems lacking: $62.2 \%$ think that 
"you can never be too careful when dealing with others," versus $36 \%$ who believe that "you can trust the majority of people." These levels of generalized trust have remained quite stable over the last four decades (Analistas Socio-Políticos 2016). Second, in choosing an option from the statement "the majority of people in Spain try to do their job very well or they just try to comply," $61.5 \%$ opted for the latter and $33.4 \%$ for the former. Thus, the idea is very widespread that the Spanish are not very trustworthy in terms of doing things well - which is fundamental, as we depend on others to meet our expectations. Third, respondents were asked to choose which of two descriptions "better describes what occurs in Spain: a job well done tends to be recognized or rewarded or a job well done tends to meet with silence or indifference?" Most (75.8\%) chose the second alternative and only $18.5 \%$ the first.

This portrays a relatively untrustworthy society, whose members are careless about their own work and indifferent or silent towards those who do it right. This does not accord with a high propensity to get involved in civic action. If society does not have great trust in its politicians or in itself, it may tend toward despondency or irritation, leading to indolence and/or explosions of indignation. Yet the possibility remains that society could develop its ability to use its common sense and moral sense, of which the survey has left many indications. Once more, what we are referring to is not a predetermined story, but rather an open and contradictory drama.

\section{/// Conclusion: An Open and Dramatic Process}

This article is written from the perspective of interpretive sociology. It is based on a social theory that attempts to integrate the dimensions of structure and agency in an open and dramatic temporal process, and locates culture and meaning at its centre. Relationality, reflexivity, and civic impulse are interconnected. Relationality refers to agents being in relationship with each other in such a way that their decisions and choices (their projects, their voices) can only be understood as proposals and responses to other agents. What I have referred to in this study as "the voice of the audience" is exactly that: a sort of proposal and response of the common people, the citizens seen as spectators, to other voices, in particular, to the proposals and responses of "the actors on the stage," the elites and counter-elites of the moment. Reflexivity is common to all these agents. It is their capacity to be conscious of the meaning they attribute to their acts, and to their capacity to understand the meaning that others attribute to 
them. But it is also their capacity to learn from the consequences of their actions. Of course, this learning process is problematic, because it is possible to extract both correct and incorrect conclusions from experiences. In other words, the learning process can be affected by an increase in entropy, a risk that exists in all social processes, without the proper inputs of intelligence and moral sentiment.

In the case that concerns us, I have stressed the core of reasonableness (the sense of reality, the common sense) and decency (the moral sense) of the majority of the common people in Spain in the current crisis situation. I have done so by understanding, analysing, and explaining their voice, but also by situating it among a chorus of voices involved in managing the crisis. The voice of the Spanish citizens differs from the voices of the elites and their milieus, both those of the establishment and the anti-establishment. I also defend this voice, that is, I favour the historical possibility of a reasonable and reconciled (but not homogeneous) society, with the hope that this facilitates discussion and strengthens the plausibility of the interpretation. The approximate realization of such a society seems to me possible under the current historical conditions, and preferable as well, as it is relatively better than the available alternatives. Such support, being relative, leaves the door open for rectifications of greater or lesser scope. Ultimately, it is the support for a "civil society" sensu lato (Pérez-Díaz 2014).

I will not reiterate the main points and findings of my study by considering society's messages and socio-cultural resources. Instead, I conclude with two observations.

First, the key to developing the potential of society's civic impulse is perhaps in coming to terms with the starting point of all the agents involved, namely the sense of their limits, which could, along with a sufficient dose of civic passion, transform the meaning of the political experience. The message of our audience could be interpreted as calling into question the way many politicians do politics. It seems based on an appreciable dose of good sense, and, to a point, sounds like an echo of ancient wisdom, which might prepare us to manage these coming intoxicating times soberly. As pointed out by Perelman and Olrechts-Tyteca (1971; see also Jaeger 1986), the ultimate effort of Demosthenes was to appeal to the people so that he himself could improve, as a way of improving his politics; hoping that their reasonable and virtuous voice could educate their leaders. We ought to imagine that in today's Spain we have something like an audience that, in an exercise of pedagogy and a colloquial key, would tell its politicians the following: 
"Do not imagine that you are going to set us on a course, adopting a prophetic air (we say this without disdain for the authentic prophets that emerge from time to time). We are all already set on our course, and have been for some time, after many vicissitudes, and through a network of decisions, institutional pressures, and external influences. We accept it; we do not essentially question it. It is not a course toward the ideal city, but perhaps it is the best course possible, given the circumstances. Nor is it necessary that you adopt a radical position that questions the framework of political and economic life, or that you defend and maintain it at all costs; we prefer relative moderation, continual reforms-although sometimes quite deep - and reasonable adjustments. Nor is it necessary that you overdramatize the issue of collective identity, with such anger or disdain toward your adversaries of the moment: we are showing you a predisposition to accept and live with complex identities. In general, do not engage in so much fighting among yourselves; it is not necessary that you affirm your leadership in that way: we are telling you, both actively and passively, that we prefer more civil forms of political relationships. Our disaffection with you is clear, but it only exists up to a point. You should not be indignant about it, or be overwhelmed by it, or deny it. Notice that we do not feel hostile to you, but rather ambivalent: this could change and might diminish if you react with good sense. And yes, we recognize that our weakness, apart from a deficit in our knowledge, is a lack of trust in ourselves and of civic impulse. Perhaps this is an issue where, realistically, we should not expect much from you. In any case, in this respect, it is our own responsibility that is at stake."

Yet, clearly, to be fair, and as corresponds to the open character of the ongoing drama, a second observation must be added to the audience's discourse. Namely, that a potential exists not only for the best from the citizenry, but also for the worst. The potential for the best is not a result of the development of the capacity for adaptation, which, by itself, might be a form of mere survival, of resignation to indefinitely maintaining a variant of the status quo. Instead, it is the potential for a more noble, more reasonable and just form of doing politics. The citizenry can aspire to more if their reflexivity, the quality of their social relations, and their civic impulse substantially improves. At the same time, the potential for the worst implies the common people's further steps toward achieving their own self-centred interests at whatever cost, and of their being carried away by a mix of irritability and passivity concerning common affairs, and perhaps, in following this path, of ending up in a state of more or less conscious and 
voluntary servitude to the oligarchs or demagogues of the moment. Or of relapsing into such a state again and again.

Bibliography:

/// Analistas Socio-Políticos. 2016. Avance de resultados de la encuesta 'Retos a la democracia and el espacio público en España, y en Europa, en la crisis actual', http://www.funcas.es/publicaciones/Docs/AvanceDeResultadosDeLaEncuesta.pdf, accessed 05.09.2017.

/// Archer M.S. 2007. Making Our Way through the World: Human Reflexivity and Social Mobility, Cambridge University Press.

/// Archer M.S. 2010. Introduction: The Reflexive Re-turn, [in:] Conversations about Reflexivity, ed. M.S. Archer, Routledge, pp. 1-13.

/// Bakhtine M. 1970. Problèmes de la poétique de Dostoïevski, L'Age d'Homme.

/// Caplan B. 2002. Systematically Biased Beliefs About Economics: Robust Evidence of Judgmental Anomalies from the Survey of Americans and Economists on the Economy, "The Economic Journal", vol. 112(479), pp. 433-458.

/// Davidson D. 1974. On the Very Idea of a Conceptual Scheme, "Proceedings and Addresses of the American Philosophical Association", vol. 47, pp. $5-20$.

/// Donati P. 2011. Relational Sociology: A New Paradigm for the Social Sciences, Routledge.

/// Foster G.M. 1967. Peasant Society and the Image of Limited Good, [in:] Peasant Society: A Reader, eds. J.M. Potter, M.N. Diaz, G.M. Foster, Little, Brown and Company, pp. 300-323.

/// Friedman J. 2009. A Crisis of Politics, Not Economics: Complexity, Ignorance, and Policy Failure, "Critical Review", vol. 21(2-3), pp. 127-183.

/// Gadamer H.-G. 1996. Vérité et méthode. Les grandes lignes d'une hermeneutique philosophique, Éditions du Seuil.

/// Granovetter M. 1985. Economic Action and Social Structure: The Problem of Embeddedness, "American Journal of Sociology", vol. 91(3), pp. 481-510.

/// Greenfeld L. 2006. Nationalism and the Mind, Oneworld. 
/// Hall J.A. 2013. The Importance of Being Civil: The Struggle for Political Decency, Princeton University Press.

/// Jaeger W. 1986. Demóstenes, Fondo de Cultura Económica.

/// Kojève A. 1947. Introduction à la lecture de Hegel, Gallimard.

/// Lamont M. 2000. The Dignity of Working Men: Morality and the Boundaries of Race, Class, and Imagination, Harvard University Press.

/// MacIntyre A. 2006. The Taskes of Philosophy, Selected Essays, vol. 1, Cambridge University Press.

/// March J.G., Olsen J.P. 1995. Democratic Governance, Free Press.

/// Morris I., Manning J.G. 2005. Introduction, [in:] The Ancient Economy: Evidence and Models, eds. J.G. Manning, I. Morris, Stanford University Press, pp. $1-44$.

/// Nora P., ed. 1997. Les lieux de mémoire 2, Gallimard.

/// Perelman C., Olbrechts-Tyteca L. 1971. The New Rhetoric: A Treatise on Argumentation, University of Notre Dame Press.

/// Pérez-Díaz V. 1980. Introducción a la Sociología: ensayo sobre la ciencia social en su historia, Alianza.

/// Pérez-Díaz V. 1991. Structure and Change of Castilian Peasant Communities: A Sociological Inquiry into Rural Castile 1550-1990, Garland.

/// Pérez-Díaz V. 2008. El malestar de la democracia, Crítica.

/// Pérez-Díaz V. 2013. Introduction: The Crisis in Europe and the Euro Problem, [in:] Europe and the Global Crisis, ed. V. Pérez-Díaz, Gota a Gota, pp. 9-39.

/// Pérez-Díaz V. 2014. Civil Society: A Multi-Layered Concept, "Current Sociology", vol. 62(6), pp. 812-830.

/// Pérez-Díaz V. 2015. La intensidad de agencia, su anclaje and su paisaje: clase obrera y elites, mercado de trabajo and cultura en la España actual, [in:] V. PérezDíaz, J.C. Rodríguez, J.P. López-Novo, E. Chuliá, Agentes sociales, cultura and tejido productivo en la España actual, Funcas, pp. 17-87.

/// Pérez-Díaz V. 2017. The Voice of Society in the Face of the Crisis, Funcas. Available at: https://www.funcas.es/publicaciones/Sumario. aspx?IdRef $=24-24003$, accessed 10.10.2017. 
/// Pérez-Díaz V., Mezo J., Rodríguez J.C. 2012. La crisis y las autonomías. La sociedad española ante la crisis económica y el sistema de las autonomias, Funcas.

/// Pérez-Díaz V., Rodríguez J.C. 2010. Alerta and desconfiada. La sociedad española ante la crisis, Funcas.

/// Polanyi K. 2001 [1944]. The Great Transformation: The Political and Economic Origins of Our Time, Beacon Press.

/// Putnam R.D. 2000. Bowling Alone: The Collapse and Revival of American Community, Simon \& Schuster.

/// Quine W.v.O. 1960. Word and Object, MIT Press.

/// Smelser N.J. 1998. The Rational and the Ambivalent in the Social Sciences: 1997 Presidential Address, "American Sociological Review", vol. 63(1), pp. $1-16$.

/// Smelser N.J., Swedberg R. 2005. Introducing Economic Sociology, [in:] The Handbook of Economic Sociology, eds. N.J. Smelser, R. Swedberg, $2^{\text {nd }}$ ed., Princeton University Press, Russell Sage Foundation, pp. 3-25.

/// Smith P.D. 2002. The Virtue of Civility in the Practice of Politics, University Press of America.

/// Streeck W. 2014. How Will Capitalism End?, "New Left Review", vol. 89, pp. 35-64.

/// Tetlock P.E. 2005. Expert Political Judgment: How Good Is It? How Can We Know, Princeton University Press.

/// Thompson E.P. 1971. The Moral Economy of the English Crowd in the Eighteenth Century, "Past and Present", vol. 50(1), pp. 76-136.

/// Wuthnow R. 2005. New Directions in the Study of Religion and Economic Life, [in:] The Handbook of Economic Sociology, eds. N.J. Smelser, R. Swedberg, $2^{\text {nd }}$ ed., Princeton University Press, Russell Sage Foundation, pp. 603-626.

\section{/// Abstract}

The strategic capacity of human agency to orient itself in a context of growing uncertainty and complexity depends on the degree and quality of its reflexivity and relationality, and of the civic impulse arising from the connection between both. The present article explores this capacity by 
analysing the results of an opinion survey carried out in May 2016, and by developing an argument about one collective agent: the Spanish citizenry. Spanish citizens send three main messages. First, they opt for a European course and for a range of policies consistent with convergence (and debate) between the traditions of social democracy and conservative liberalism. Second, they are attentive to the task of recreating a political community. Third, they ask for civil forms of doing politics. To send these messages they draw on socio-cultural resources, and forms of reflexivity and relationality. The article addresses society's relations with the political class and with itself and the cultural resources (economic knowledge, historical narratives) that map these relationships within their global context and their past.

Keywords:

ambivalence, reflexivity, relationality, civility, Spain

/// Víctor Pérez-Díaz-president of Analistas Socio-Políticos Research Center (Madrid). Member of the American Academy of Arts and Sciences and of the Academia Europaea. Ph.D. in sociology, Harvard University. He has been professor of sociology at the Complutense University of Madrid and visiting professor at Harvard University, MIT, and the University of California. Author of more than forty books, including The Return of Civil Society (1993; Polish edition: Powrót Spoleczenstwa Obywatelskiego w Hiszpanii, 1996) and Markets and Civil Society (2009).

E-mail:vperezdiaz@asp-research.com 
